\title{
Left ventricular mechanical dyssynchrony as a target for therapy in patients with left ventricular aneurysm
}

\author{
Yaron Aviv, MD, and Nili Zafrir, MD, FESC, FASNC ${ }^{\mathrm{a}}$ \\ a Department of Cardiology, Rabin Medical Center, Tel Aviv University, Petah Tikva, Israel
}

Received Oct 8, 2020; accepted Oct 9, 2020

doi: $10.1007 / \mathrm{s} 12350-020-02431-7$

\section{See related article, pp. 652-660}

Left ventricular (LV) mechanical dyssynchrony (MD) represents dyskinetic myocardium or myocardial scar tissue which "pushes outwards" during systole, and has been shown previously to be and independent marker of poor outcome. ${ }^{1}$ Dyssynchronous myocardium is deleterious twice over-the reduction in ejection fraction is further complicated by the inability of the myocardium to effectively increase $\mathrm{LV}$ end systolic pressure, accelerating negative remodeling and straining the remaining healthy muscle tissue.

It is often associated with a prolonged QRS duration such as Left Bundle Branch Block, but as has been shown previously in the VALIANT study concentrating on heart failure patients, LVMD is associated with a poor prognosis even in patients with QRS duration $<120 \mathrm{~ms} .{ }^{2}$ In the post-MI population, LVMD was more closely associated with a poor prognosis than QRS width. $^{3,4}$

It is a finding which is often described in Echocardiography (via 2D $3 \mathrm{D}$ speckle tracking), ${ }^{1}$ but can be quantified via analysis of phase histograms in gated SPECT myocardial perfusion imaging, in both rest and stress perfusion imaging.

Regional samples of thickening and movement are obtained throughout the cardiac cycle, and the phase angle of initiation of contraction of the myocardium is calculated for each region and presented as distribution

Reprint requests: Nili Zafrir, MD, FESC, FASNC, Department of Cardiology, Rabin Medical Center, Tel Aviv University, Petah Tikva, Israel; zafrirmd@isdn.net.il

J Nucl Cardiol 2022;29:661-2.

$1071-3581 / \$ 34.00$

Copyright (C) 2020 American Society of Nuclear Cardiology. on a phase histogram. The bandwidth (width of the histogram, BW) represents synchrony or dyssynchrony-the higher the bandwidth, the more dyssynchronous the mechanical contraction. Dyssynchrony could also be represented on a phase polar map by the distribution the angles of initiation of contraction-the more heterogeneous are the angles (represented as SD), the greater the dyssynchrony. ${ }^{5}$

It is an automatic process which is highly reproducible and independent of the operator, unlike echocardiography.

In this issue of the journal is published a small retrospective study by $\mathrm{Xia} \mathrm{Lu} \mathrm{et} \mathrm{al.,} \mathrm{in} \mathrm{which} \mathrm{the} \mathrm{authors}$ sought to demonstrate the prognostic capabilities of LVMD by SPECT imaging in a cohort of post-MI patients with LV aneurysm. ${ }^{6}$

Despite the small cohort, dyssynchrony, measured by histogram bandwidth $\left(>90^{\circ}\right)$, was significantly associated with a poor outcome and a marker for cardiovascular mortality in patients with LV aneurysm. The authors further sought to better define the subgroup of patients who would most likely benefit from aneurysm resection surgery, a high-risk procedure which is rarely performed today due to perioperative mortality and morbidity.

The authors have shown benefit in LV aneurysm patients who previously demonstrated LVMD per gated SPECT. They found that patients with $\mathrm{LVEF} \leq 25 \%$ and LVMD had higher mortality rate than patients with LVEF $>25 \%$ and without LVMD. However, in this study it ought to be emphasized that none of the patients underwent CRT or CRTD during follow up which may influence outcome. Second, in most of the studies and publications regarding LVMD, the main predictor of outcome was increased SD and not $\mathrm{HB}$ as shown in this study. This may be related to wall motion variability in patients with LV aneurysm, who were the focus in this article. 
This served as further proof of SPECT functionality in assessing LVMD. Previously, The PROSPECT study failed to show LVMD as demonstrated by echocardiography is a prognostic marker for a response to $\mathrm{CRT}^{7}{ }^{7}$ but this was due to several methodological issues and the high inter-observer variability of echo studies. However, where Echocardiography has failed, perfusion imaging studies have succeeded in showing promise in predicting response to CRT in small scale trials. ${ }^{8,9}$

Another study also demonstrated perfusion imaging's ability to predict ventricular arrhythmias even after implantation of a CRT device in patients suffering from mechanical dyssynchrony. ${ }^{9}$ This is likely due to increased strain at scar's edges. Phase SD was previously identified as an independent predictor for cardiac death ${ }^{10}$ even after ICD implantation. ${ }^{11}$ It might be of interest to study patients with $\mathrm{LV}$ aneurysm in respect of beneficial effect of CRT or CRTD.

In a previous study, multivariate analysis in patients undergoing MPI GSPECT, LVMD was closely associated with adverse outcome as measured by phase SD (for each $10^{\circ}$ increment in the phase angle of initiation), as much so as NYHA, and more so than ejection fraction. ${ }^{12}$

To summarize, left ventricular mechanical dyssynchrony is a readily available marker in heart failure, which if present can serve to heighten the physician's awareness to possible negative outcomes on the one hand, but possible positive response to invasive heart failure treatment on the other hand. The work by Xia $\mathrm{Lu}$ et al shows a novel use of LVMD in directing the treatment of LV aneurysm patients.

Future larger scale studies are needed to better define the role of nuclear cardiology assessed mechanical dyssynchrony in the treatment of LV aneurysm patients.

\section{References}

1. Modin D, Biering-Sørensen SR, Møgelvang R, Jensen JS, BieringSørensen T. Prognostic importance of left ventricular mechanical dyssynchrony in predicting cardiovascular death in the general population. Circ Cardiovasc Imaging 2018;11:e007528.
2. Shin SH, Hung CL, Uno H, Hassanein AH, Verma A, Bourgoun $\mathrm{M}$, et al. Mechanical dyssynchrony after myocardial infarction in patients with left ventricular dysfunction, heart failure, or both. Circulation 2010;121:1096-103.

3. Hess PL, Shaw LK, Fudim M, Iskandrian AE, Borges-Neto S. The prognostic value of mechanical left ventricular dyssynchrony defined by phase analysis from gated single-photon emission computed tomography myocardial perfusion imaging among patients with coronary heart disease. J Nucl Cardiol 2017;24:48290.

4. Zafrir N. Left ventricular mechanical dyssynchrony in patients with coronary artery disease. J Nucl Cardiol 2017;24:491-3.

5. Chen J, Garcia EV, Bax JJ, Iskandrian AE, Borges-Neto S, Soman P. SPECT myocardial perfusion imaging for the assessment of left ventricular mechanical dyssynchrony. J Nucl Cardiol 2011;18:685-94.

6. Lu X, Zhao M, Tian C, Wei H, Gao M, Yang X, et al. Prognostic value of ventricular mechanical dyssynchrony in patients with left ventricular aneurysm: A comparative study of medical and surgical treatment. J Nucl Cardiol 2020:Available online.

7. Chung ES, Leon AR, Tavazzi L, Sun JP, Nihoyannopoulos P, Merlino J, et al. Results of the predictors of response to crt (prospect) trial. Circulation 2008;117:2608-16.

8. Henneman MM, Chen J, Dibbets-Schneider P, Stokkel MP, Bleeker GB, Ypenburg C, et al. Can LV dyssynchrony as assessed with phase analysis on gated myocardial perfusion SPECT predict response to CRT? J Nucl Med 2007;48:1104-11.

9. Boogers MM, Van Kriekinge SD, Henneman MM, Ypenburg C, Van Bommel RJ, Boersma E, et al. Quantitative gated SPECTderived phase analysis on gated myocardial perfusion SPECT detects left ventricular dyssynchrony and predicts response to cardiac resynchronization therapy. J Nucl Med 2009;50:718-25.

10. Zafrir N, Bental T, Strasberg B, Solodky A, Mats I, Gutstein A, et al. Yield of left ventricular dyssynchrony by gated SPECT MPI in patients with heart failure prior to implantable cardioverterdefibrillator or cardiac resynchronization therapy with a defibrillator: Characteristics and prediction of cardiac outcome. J Nucl Cardiol 2017;24:122-9

11. Tsai SC, Chang YC, Chiang KF, Lin WY, Huang JL, Hung GU, et al. LV dyssynchrony is helpful in predicting ventricular arrhythmia in ischemic cardiomyopathy after cardiac resynchronization therapy a preliminary study. Med (United States). 2016;95:e2840.

12. Zafrir N, Nevzorov R, Bental T, Strasberg B, Gutstein A, Mats I, et al. Prognostic value of left ventricular dyssynchrony by myocardial perfusion-gated SPECT in patients with normal and abnormal left ventricular functions. J Nucl Cardiol 2014;21:53240.

Publisher's Note Springer Nature remains neutral with regard to jurisdictional claims in published maps and institutional affiliations. 